\title{
Review Article \\ Defining Product Lifecycle Management: A Journey across Features, Definitions, and Concepts
}

\author{
Angelo Corallo, ${ }^{1}$ Maria Elena Latino, ${ }^{1}$ Mariangela Lazoi, ${ }^{1}$ Serena Lettera, \\ Manuela Marra, ${ }^{2}$ and Sabrina Verardi ${ }^{2}$ \\ ${ }^{1}$ Dipartimento di Ingegneria dell'Innovazione, Università del Salento, Campus Ecotekne, 73100 Lecce, Italy \\ ${ }^{2}$ Incubatore EuroMediterraneo, Università del Salento, Campus Ecotekne, 73100 Lecce, Italy \\ Correspondence should be addressed to Mariangela Lazoi; mariangela.lazoi@unisalento.it
}

Received 27 April 2013; Accepted 8 July 2013

Academic Editors: T.-M. Choi and B.-S. Liu

Copyright (C) 2013 Angelo Corallo et al. This is an open access article distributed under the Creative Commons Attribution License, which permits unrestricted use, distribution, and reproduction in any medium, provided the original work is properly cited.

Product lifecycle management (PLM) has become more important in companies providing technologies and methodologies to manage data, information, and knowledge along the whole product lifecycle. In recent years, several authors have argued about PLM using a managerial or a technological view. The paper analyses these studies and integrates different author's points of view using focus groups, blogs, and face-to-face meetings in a university community of practice. Three sets of features (i.e., managerial, technological, and collaborative ones) have been used to review the existing definitions shared between academic and industrial ones and to propose an extended PLM definition describing its key concepts. The paper is a useful reference for managers and academics who want to have a clear and critical understanding of PLM using a unique source to collect lines of evidence on several PLM definitions, features, and concepts.

\section{Introduction}

Continuous innovation, global collaboration, risk management in complex projects, and rapid technological changes are challenges that compel large and small enterprises to react by focusing on core competence, collaborating with partners in product design, engineering and production, or shifting part of the activities in low labor cost countries.

Producing complex products in this scenario requires that information about product and process is accessible to the several actors in the value network such as partners, suppliers, and customers. The tendency is to use a PLM strategy to integrate people, processes, business systems, and information in order to manage the product development [1] and support its lifecycle.

PLM means product lifecycle management, and its value is increasing, especially for manufacturing, high technology, and service industries [2]. In fact, today PLM is widely recognized as a business necessity for companies to become more innovative in order to meet current challenges such as product customization and traceability, growing competition, shorter product development and delivery times, globalization, tighter regulations, and legislation. Being an innovative business, it does not simply mean creating innovative products, but it also means improving the processes a company uses to realize its products and how it supports them using innovative approaches for a complete product lifecycle [3]. In fact, the aim of PLM is to trace and manage all the activities and flows of data and information during the product development process and also during the actions of maintenance and support in order to identify a new business model that integrates engineering processes and different ICT tools [4]. Working in this direction, PLM enables companies to satisfy the innovative needs of their business.

Different ICT systems contain knowledge about the products (e.g., CAD, CAM, PDM, NC, and $\mathrm{CM}$ ), and the PLM ones allow to integrate all of them [5, 6]. PLM systems are the enabling technology for PLM [7]; they serve as a central hub [8] for product data supporting the collaborative product design and development and the use and management of information in the whole network of actors (i.e., in an extended enterprise) involved in the realization of the product [4]. 
Therefore, PLM is a holistic business concept [2]; it is both a business approach and a software solution, which during the last years has evolved from a set of engineering oriented tools into an enterprise-level solution [9].

Looking at the literature and web sources, several definitions of PLM are actually available. These definitions have been designed in different contexts; they come from global consulting and research firms, online PLM communities, government agencies, technology and software vendors, universities and academic communities, worldwide PLM experts, and companies from various industries that have implemented a PLM project. All these definitions can be easily shared among industrial and academic definitions or depending on the emphasized perspective: some focused on technological applications, others on processes or strategies, but many of them are very similar.

Furthermore, given the importance and criticality of PLM for the companies, already some authors $[4,6,10]$ have attempted to analyze the definitions available in the literature in order to synthesize their own contribution. Each analysis available in the literature has been designed on the strict point of view of each author, and it is based on their personal and professional experience.

Evolving from the experience in a PLM community of practice (Co.PLM) of a research center in the University of Salento (Italy), the paper aims to define PLM integrating all its main features and concepts relevant both for managerial and theoretical purposes. To reach this aim an exploration of the PLM features, available definitions, and main treated concepts has been carried out. The research method has been based on three phases (i.e., starting, analysis, and validation) that use focus groups, a community blog, and face-to-face meetings to analyze the existing PLM definition evaluating three sets of features-managerial, technological, and collaborative ones-and elaborating a new definition. The paper is, in fact, original in the research approach used to create a PLM definition and in the proposed results that include a holistic PLM definition and a set of PLM features useful to guide future research.

The remaining of the paper is composed of four sections. Section 2 explains the research design highlighting the context of research, the method used, and the features analyzed. In Section 3, industrial and academic definitions have been examined with respect to the specified features. Section 4 proposes the extended PLM definition of the community Co.PLM and describes the related key concepts. A last, section of conclusion ends the paper.

\section{Research Design}

2.1. Research Context. The research has been carried out in the "collaborative product design management" (cPDM) laboratory of the "Centro Cultura Innovativa d'Impresa" (University of Salento); it aims to support companies in the field of product design and development and to lead the research to new perspectives and findings. It is composed of about 60 researchers distributed among professors, fellows, senior, and young researchers, and Ph.D. students.
The research activities of the laboratory concentrated on complex products such as automotive, naval, and aerospace ones and proposed technological solutions for improving the companies' practices. The laboratory is made up by several groups focusing on different research areas: simulation methodologies and data management, automation, product lifecycle data management, knowledge security, business process management, service engineering, energy and additive manufacturing, social network, and impact analysis. Each group is involved in several Italian and European projects including academic and industrial partners.

Since the product lifecycle management is a topic common to several cPDM Lab groups, a community of practice, called Co.PLM, has been established to improve knowledge sharing and integration.

Co.PLM means collaboration on PLM and aims to support the dissemination of practices on PLM within the laboratory and to the external partners. The three main goals of the community are the development of common research topics, the sharing of lessons learnt and best practices, and the collaborative problem solving about PLM topics. The community is composed of 23 members distributed on three work groups: PLM standards, PLM background and PLM software. The first work group wants to provide an overview on the international standards used in the different phases of products, processes, and services lifecycle. The second one aims to analyze the PLM literature in order to systematize the available findings and to highlight existing gaps defining future research lines. Finally, the third work group wants to analyze the functionalities of open-source and proprietor software realizing a complete benchmarking on the existing PLM systems.

2.2. Research Problem and Method. In order to improve the sense of belonging to the community, the need to give a common meaning for PLM has emerged. Several definitions are available in the literature, both from industrial and academic sources, but there is not a unique one that includes all the aspects emerging from Co.PLM practices and knowledge. Therefore, the paper aims to answer the research question "what is PLM?" proposing a definition and describing each element (i.e., features and concepts) that characterizes it.

To address the research question, the collaboration among the community researchers had a central role to overcome biases and limits of an isolated researcher's work and to reach a common and wide accepted result, emerging from discussions and reflections conducted both in virtual and face-to-face sessions. For these aims the research design is shared on three main phases: starting phase, analysis phase, and validation phase (Table 1 ).

During the starting phase, the features of PLM relevant to the community have been specified with the involvement of all the members of the Co.PLM community. Each member has described its own work activities and interest on PLM in order to share the available knowledge with the whole community. Later, a set of literature definitions has been collectively read and discussed highlighting the more interesting features of PLM. This phase has been developed following 
TABLE 1: Research phases.

\begin{tabular}{lcc}
\hline Starting phase & Analysis phase & Validation phase \\
\hline At the whole community & At PLM Background work group & At the whole community \\
Tool: focus group & Tool: blog, face-to-face meetings & Tool: blog, focus group \\
$\begin{array}{l}\text { Findings: } \\
\text { three sets of PLM features }\end{array}$ & Findings: & Findings: \\
& (i) critical review & a final PLM definition \\
\hline
\end{tabular}

the focus group method $[11,12]$ and the specific topic of "what PLM is" has been deeply investigated. All the members have discussed the topic of PLM proposing what they know about it.

The starting phase has been concluded with the characterization of three sets of relevant features to analyze the available PLM definitions:

(i) managerial features about business behaviors and processes;

(ii) technological features about the main capabilities and characteristics of a PLM system;

(iii) collaborative features about the relationships and cooperation needs during the activities of PLM.

For each set, some key dimensions have been highlighted to drive a more careful analysis of PLM definitions. In Table 2 the three sets of features and a brief description of their key dimensions are summarized.

The analysis phase has used these features for reviewing the PLM definitions available in the state of the art; the aim has been to describe for each of them the main insight and to underline the lack or the surplus of the specified key dimensions. This phase has been developed inside the work group "PLM Background", and all the related members have been involved. A dedicated blog on the Co.PLM website has been launched to support the discussion and lead to a final definition. The blog with the discussions has been always available to the whole community in order to grasp further feedbacks. Inside the blog, all the initial definitions discussed in the starting phase plus other definitions emerging from a further literature and websites exploration have been inserted. The definitions have been shared between industrial and academic contributions. Industrial definitions, available on websites and white papers, come from research companies, software vendors, standard institutions, and online communities; instead, the academic definitions have been proposed by scientific representatives and experts, and they are available on scientific journals, conference proceedings, or books.

Each definition has been discussed both on the blog and during face-to-face meetings evaluating the congruence or not in respect to the features specified in the starting phase. During this phase, the literature has been explored, and collaborative ICT tools have been used to support the knowledge sharing among the community members leading to the new definition. In fact, since none of the available definitions allow to provide a comprehensive view on the
PLM for the community matching each of the identified features, a new definition has been developed.

Finally, the validation phase has aimed to validate the developed definition in a community meeting where all the Co.PLM members have participated. The definition has been available on the website for a week before the community meeting, and the members have been invited to reflect on it and to post feedbacks. During the meeting, all the aspects related to the definition have been discussed following a focus group approach. Some improvements emerged and led to the final definition that has been accepted by the $90 \%$ of the members as the PLM identity card of the community.

\section{Critical Review of PLM Definitions}

3.1. Industrial Definitions. CIMdata (2002), a research firm focused on PLM, proposes a very comprehensive definition: "PLM is a strategic business approach that applies a consistent set of business solutions in support of the collaborative creation, management, dissemination, and use of product definition information across the extended enterprise, and spanning from product concept to end of life-integrating people, processes, business systems, and information. PLM forms the product information backbone for a company and its extended enterprise."

The first important aspect that emerges is a new way to conceive PLM: "a strategic business approach.” The classical conception that views PLM as a set of technologies is outdated. CIMdata uses the word "approach" to capture all the various elements composing PLM, and it underlines the ability to integrate "people, processes, business systems and information" [3]. The adjectives "strategic business" used for "approach" underline the need to manage the entire product lifecycle to obtain business efficiency and effectiveness. In fact, a correct management of product lifecycle enables the enterprise to obtain competitive advantages creating better products in less time, at lower cost, and with fewer defects [13]; in other words it creates value for the company. CIMdata draws the PLM boundaries in space and time, respectively, with the concepts of "extended enterprise" and product lifecycle "from concept to end of life." It refers to the need of an increasing number of companies to share product information outside the enterprise, in order to improve collaboration in the product development. The complexity of data management is proportional both to the length of product life and to the number of product components. Therefore, PLM represents a "product information backbone" containing data coming from the internal and external members involved in the product development process. Even if PLM is considered 
TABLE 2: Features, dimensions, and description.

\begin{tabular}{|c|c|c|}
\hline Set of features & Key dimensions & Description \\
\hline \multirow{4}{*}{ Managerial features } & Integrated approach & $\begin{array}{l}\text { It means the act of dealing with PLM considering its different related } \\
\text { aspects (e.g., information, technology, and strategic points of view). }\end{array}$ \\
\hline & Business strategy & $\begin{array}{l}\text { It is how an organization takes decisions and manages resources to } \\
\text { gain and maintain a competitive advantage over a period of time. }\end{array}$ \\
\hline & Creating value & $\begin{array}{l}\text { It is the primary goal of every business; it means performing activities } \\
\text { that increase the value of organization's goods or services, generating } \\
\text { wealth for its shareholders, and satisfying customers' expectations. }\end{array}$ \\
\hline & $\begin{array}{l}\text { Design, production, and } \\
\text { maintenance phases }\end{array}$ & $\begin{array}{l}\text { They refer to the different stages of the entire product lifecycle from its } \\
\text { conception, through design and manufacture, to service and disposal. }\end{array}$ \\
\hline \multirow{5}{*}{ Technological features } & $\begin{array}{l}\text { Product information } \\
\text { backbone }\end{array}$ & $\begin{array}{l}\text { It means a central hub storing different data distributed among } \\
\text { heterogeneous systems; it creates a single view of product information } \\
\text { that can be leveraged across the whole organization and its network. }\end{array}$ \\
\hline & IT tools (CAX, PDM, etc.) & $\begin{array}{l}\text { They encompass a board range of software and IT systems used in all } \\
\text { the aspects of product lifecycle (design, analysis, manufacturing, } \\
\text { production planning, product testing, collaboration, etc.). }\end{array}$ \\
\hline & Secondary information & $\begin{array}{l}\text { It is all the information indirectly connected to the specific product } \\
\text { knowledge (e.g., vendor application notes, catalogs, customer } \\
\text { feedbacks, marketing plans, archived project schedules, etc.). }\end{array}$ \\
\hline & Traceability & $\begin{array}{l}\text { It means the ability to chronologically interrelate product lifecycle } \\
\text { information and to track all accesses and changes to the data. }\end{array}$ \\
\hline & Long-term archiving & $\begin{array}{l}\text { It refers to the organizational need for long-term retention of older } \\
\text { data; it helps an enterprise to maintain information integrity and } \\
\text { demonstrate regulatory compliance and transparency. }\end{array}$ \\
\hline \multirow{3}{*}{ Collaborative features } & $\begin{array}{l}\text { Integrating people, and } \\
\text { process, data }\end{array}$ & $\begin{array}{l}\text { It means combining in a unique approach different aspects related to } \\
\text { PLM (business processes, human resources, data, etc.) so that they } \\
\text { work together to better product lifecycle management. }\end{array}$ \\
\hline & Sharing & $\begin{array}{l}\text { It means using or enjoying data and information jointly with others in } \\
\text { order to enable knowledge integration during collaborations in the } \\
\text { product lifecycle. }\end{array}$ \\
\hline & $\begin{array}{l}\text { Within and across extended } \\
\text { enterprise }\end{array}$ & $\begin{array}{l}\text { It means a borderless organization whose processes are transformed } \\
\text { and integrated with the ones of its partners, based on cooperative and } \\
\text { collaborative relations. }\end{array}$ \\
\hline
\end{tabular}

a central repository of product information, the technological data features are not described.

The CIMdata definition has been one of the first contributions about this matter, and it has inspired most of the following interpretations. For example, PLM System's general manager Codrino, starting from CIMdata definition, points out that PLM allows to keep under control the "intellectual capital" necessary from when the product idea is conceived until the product becomes obsolete and unused. In particular, he defines PLM as the base of the "digital revolution" that is the ability to imagine, draw, design, build, and maintain a virtual product in a virtual factory, in other words to simulate the behavior of an object before realizing the first prototype. Then it is possible to put off the production with obvious advantages in terms of timing, cost, and quality. One of the most innovative elements in Codrino's interpretation is the introduction of the "virtual reality concept," a theme that is expanding in companies operating in forefront industries like automotive, aerospace, and medical device and that is considered fundamental for future development and competitiveness [14].
Another important contribution to PLM comes from an online community of PLM experts. PLM Technology Guide [7], a community of independent PLM consultants, defines PLM as an "all-encompassing approach" underlining the effectiveness of PLM systems to support "innovation, new product development and introduction (NPDI) and product information management from ideation to end of life." The definition focused on PLM systems ability to "integrate people, data, processes and business systems" providing "a product information backbone" available for companies and partners along the "extended enterprise." This definition does not consider several important managerial features such as business strategy and value creation; even if, it is concentrated on the technological aspects, it leaves out features such as importance of secondary information, data traceability, and long-term archiving.

Also software vendors are involved in the PLM definition issue, and they have formulated their proposal.

According to Active Sensing Inc. [15] PLM is "the process of managing product-related design, production and maintenance information"; it "also may serve as the central 
repository for secondary information." The new aspect is the idea that PLM stores data indirectly related to the product, such as "vendor application notes, catalogs, customer feedbacks, marketing plans, archived project schedules, and other information acquired over the product's life."

Instead Aras Corporation [16], an open-source PLM system vendor, underlines the importance of PLM in managing people and business processes; in particular it cites that PLM is a "process or system" to manage "anything pertaining to a product," such as people, data, and processes. Besides this definition points out the role of PLM as a "central information hub" that manages all the product data to facilitate communication about product information and to support sharing and collaboration between people through all the phases of product lifecycle. Although this definition contains the concepts of people and processes integration, it does not refer to the importance of PLM for creating value and enabling extended enterprise network.

One of the first businesses interested in PLM has been the automotive industry. An important definition that covers many features has been developed by Ford Motor Company [17]; it focused on processes, methods, and tools used during all the product lifecycle. These three factors are used together to "enable creation, update, access, and ultimately, deletion of product data." In this formulation PLM is not only considered a single tool or model, but it is also defined as something more extended and not only related just to one subset of production data. Also this definition underlines that PLM allows to extend companies across traditional boundaries and to enable collaboration overcoming geographical limits. The features of business strategy, integrated approach, and value creation are missing.

An important PLM definition has been proposed by the National Institute of Standards and Technology (NIST) that tries to investigate the best definitions of product lifecycle management proposing its point of view based on the PLM as "a vision or a business strategy for creating, sharing, managing information about product, process, people and services within and across the extended and networked enterprise covering the entire lifecycle spectrum of the product" [18]. According to this conception it is possible to underline the importance of PLM from a strategic side: its integrated product development function and its enabling capabilities (such as information management and cross-functional activity). In particular, the strategic business approach is important for "the effective management and use of corporate intellectual capital." The concept "intellectual capital" does not refer just to product data, but also to information indirectly connected to PLM such as knowledge about customers, suppliers, materials, production, and so forth. Furthermore, the concept of extended and networked enterprise is treated; it is used to underline the importance of collaboration in a global reality, referring also to the necessity of outsourcing in difficult competitive contexts. Finally, the subject of PLM considered by the NIST is the complete product lifecycle. This is not an inaccurate definition but it does not provide enough specificity to PLM; for example, it does not give any information about technological characteristics of data storage. However, the NIST definition is consistent with the pervasive view that PLM is not only an application or a system.

3.2. Academic Definitions. Garetti and Terzi [4] describe PLM as an "integrated business approach" that uses tools and IT solutions to manage product data and information. They also define PLM as a business strategy important for collaboration and for the management of data necessary to create value. In this sense, PLM includes a strategic focus on creating value "on" and "through" the product; the application of a collaborative approach to enhance core competences of several actors; the use of a large number of IT solutions for managing in a "coordinated, integrated and secure" way all the information needed to create value.

Therefore, this definition deals with the integration of data and people but not the integration of business processes; moreover it is not specifically declared that collaboration includes all the partners belonging to the extended enterprise.

Stackpole [19] proposes a PLM definition that cites "Product Lifecycle Management is an integrated, informationdriven approach" connected to "all aspects of a product's life, from its design through manufacture, deployment, and maintenance-culminating in the product's removal from service and final disposal." PLM is analyzed in a global manner with a redefinition of PLM boundaries. She underlines the importance of the organizational aspect and PLM time range (from design to disposal) that can be at least 50 years for some durable complex goods. Therefore, it is possible to notice the emerging importance of the time dimension for information, IT devices, and data preservation. In addition a PLM system is not constrained to an organization, but "PLM software suites enable accessing, updating, manipulating, and reasoning about product information that is being produced in a fragmented and distributed environment." This necessity is connected to the introduction of outsourcing for a lot of companies and this is the reason why product information can no longer be thought as confined only to the organizational boundaries. In this definition there are the emerging concepts of collaboration and extended enterprise and the focus on product information and its associated aspects (e.g., supply chains, employee knowledge management, or domain expertise) [10]. Stackpole [19] does not consider the business strategy feature, which is a fundamental element to define a successful PLM implementation. Furthermore, even if technology is described as a central point for a good PLM, the data source characteristics (e.g., consistency, traceability, and uniqueness) are not considered.

Grieves [10], in his book Product Lifecycle Management, proposes one of the most exhaustive PLM definitions that is the result of a careful analysis of some existing PLM interpretations. According to Grieves "PLM is an integrated, information-driven approach comprised of people, processes/practices, and technology to all aspects of a product's life, from its design through manufacture, deployment and maintenance-culminating in the product's removal from service and final disposal." The author underlines the PLM ability to create value through a correct information management and resumes the importance of the duration of PLM as in 
Stackpole's definition. He views PLM as an outcome of "lean thinking," the evolution of the lean manufacturing, pointing out the ability of PLM to reduce "wasted time, energy, and material across the entire organization and into the supply chain," not only during the phase of product manufacturing but also in all the product lifecycle phases. Nevertheless, the definition lacks technological features.

With a brief definition, Abramovici [20] defines PLM as "an integrated approach" that includes "a consistent set of methods, models and IT tools" for the management of "product information, engineering processes and applications" in all "the different phases of the product lifecycle." Contrary to other definitions, the author considers the integration of methods, models, and IT tools, but not of people, processes, and data; besides there is not any reference to technological data characteristics and collaborative features.

Ming et al. [13] define PLM as "a new strategic business model to support collaborative creation, management, dissemination, and use of product assets, including data, information, knowledge, so forth, across extended enterprise from concept to end of life." The novelty of this definition is the concept of strategic business model, abandoning the trend that considers PLM as an approach or a set of IT tools. According to Osterwalder et al. [21], a business model is a conceptual tool for the representation of the value that a company provides to customers, how this value is created, and the financial consequences; thus Ming states the PLM ability to create value as a business strategy. The definition underlines the role of PLM as enabler of collaboration "across extended enterprise from concept to end of life-integrating people, processes, and technology" [13]. However the aspects of product information backbone, secondary information, traceability, and long-term archiving are not considered here.

In Rangan et al. [22] PLM is viewed as a system that supports the evolution and change of data during the product lifecycle. They emphasize the relevance of PLM to "optimize business processes" as "system integrations spanning multiple phases of the product lifecycle." In this definition, PLM is not considered as a business approach that creates value for the enterprise.

According to Rachuri et al. [23], the importance of PLM is in the different phases of the product lifecycle, and it is considered as a "strategic approach" necessary to "creating and managing a company's product-related intellectual capital." They do not refer to the importance of PLM to cross geographical boundaries and to support knowledge sharing in the extended enterprise.

These last two definitions [22, 23] lack many elements, as the technological aspects of traceability and long-term archiving.

Schuh et al. [24] illustrate a PLM framework where PLM definition is a key element and provides the boundaries of process models. PLM "is not only an individual computer software, but, moreover, it is related to a broad management concept which depends on the integration of multiple software components" [24]. They develop PLM definition in seven main concepts starting from the integrated management of ideas, projects, and product portfolio, through the requirements management and ending with service and maintenance data reuse in the product development. They underline the importance of the product and processes integration, the lifecycle impact analysis, and lifecycle costs but do not refer to the sharing aspect and to the technology features.

Saaksvuori and Immonen [2] in their book, Product Lifecycle Management, consider PLM from a managerial and a technological point of view describing it as "a holistic approach that uses a wide range of different concepts, technologies, and tools," adding the collaboration perspective through the extension of "groups beyond the functions of a company or even a supply network in order to manage and control the lifecycle of a product." The authors propose a PLM definition covering every set of features discussed in this review, even if they do not deepen every key element and do not give an exhaustive characterization.

Stark [25], author of two books about PLM and founder of a PLM consulting firm, considers only managerial features, defining PLM as "the business activity of managing, in the most effective way, a company's products all the way across their lifecycles, from the beginning including development, through growth and maturity, to the end of life." Besides he emphasizes the creating value dimension describing that "the objective of PLM is to increase product revenues, reduce product-related costs, and maximize the value of products for both customers and shareholders." Stark does not consider the technological and collaborative features that have instead a primary role in this study.

\section{A Proposal of a PLM Definition}

As underlined in the review, the analyzed definitions contain reference to the managerial, technological, and collaborative features but with some limitations compared to the Co.PLM scope of analysis. Table 3 summarizes how the considered features are present or not in the reviewed definitions Table 3.

From the critical review emerges a large set of definitions covering managerial and collaborative features but in the technological field there are some gaps. In particular, the industrial category definitions are more complete: they focused on collaborative aspects and emphasized the concept of PLM as central hub of product data. Nevertheless no one of the specified definitions treats and cites aspects related to product data features in PLM approach and system. The concepts of traceability and long-term archiving that are instead very relevant to the experiences of the Co.PLM members have never been cited in any definition.

Looking at the results of the literature review, a definition has been elaborated including references and peculiarities related to all the specified features. Therefore, PLM for the Co.PLM community of practice has been defined as follows: PLM Product lifecycle management-is a strategic business approach that supports all the phases of product lifecycle, from concept to disposal, providing a unique and timed product data source. Integrating people, processes, and technologies and assuring information consistency, traceability, and long-term archiving, PLM enables organizations to collaborate within and across the extended enterprise. 


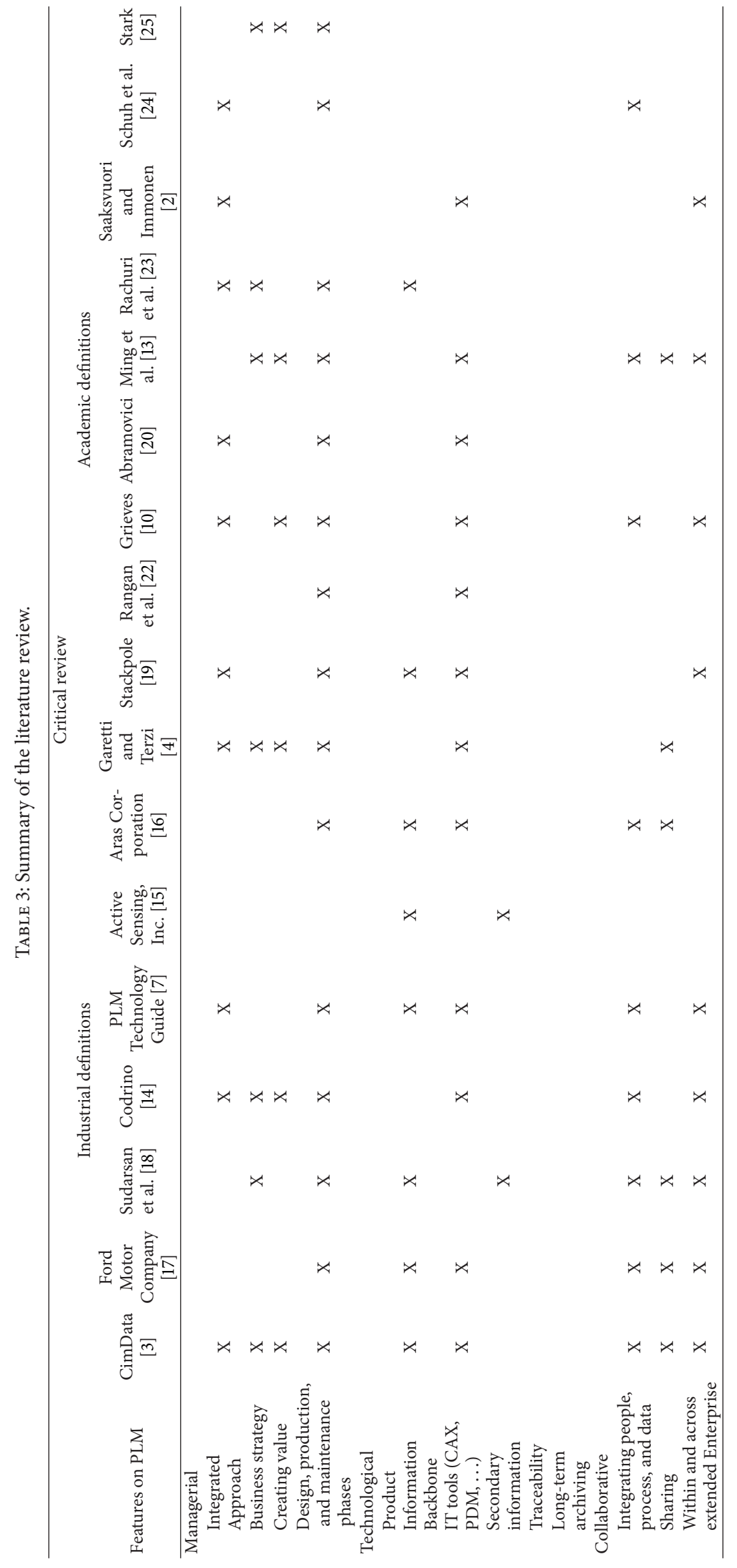




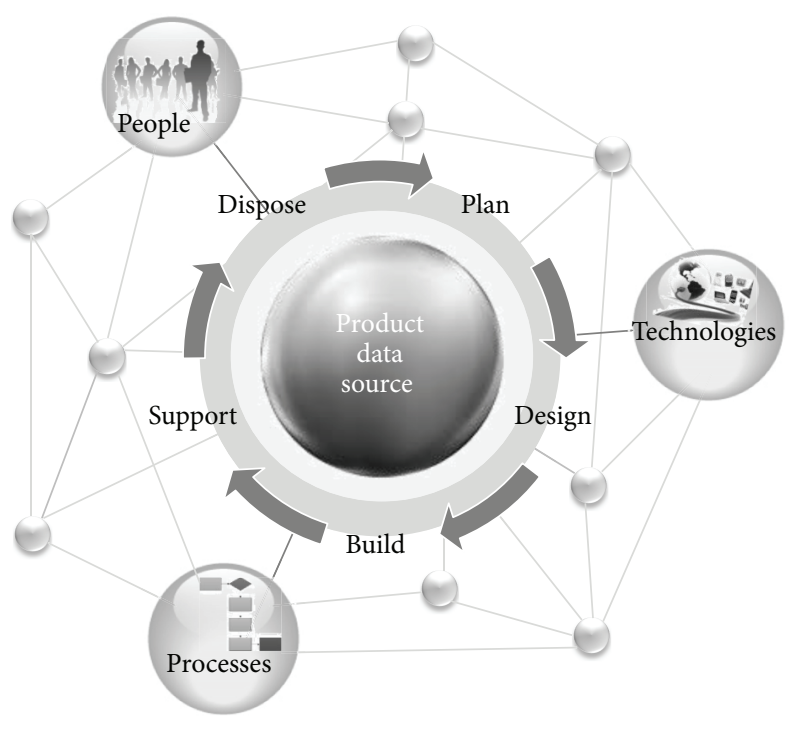

Figure 1: The PLM landscape.

A set of key concepts focalized on management, technological, and collaboration aspects are arranged around the proposed definition and can be specified in the following:

(1) strategic business approach;

(2) phases of product lifecycle;

(3) a unique and timed product data source;

(4) consistency, traceability, and long-term archiving;

(5) integrating people, processes, and technologies;

(6) collaborating within and across the extended enterprise.

They are described in the following section paying attention to the innovative aspects. Figure 1 represents graphically the PLM definition displaying how the concepts of centrality and uniqueness of a product data source and its main technological attributes (consistency, traceability, and longterm archiving) support all the product lifecycle phases; PLM data are managed by people, technological systems, and processes that are integrated and enable the collaboration in extended enterprises.

4.1. Strategic Business Approach. According to the most popular definitions (e.g., CIMdata, NIST, Grieves, and PLM Technology Guide), PLM is defined as a strategic business approach. It is better not to use the simple word technology in order not to confuse PLM with only an application or a software system and so limiting its scope. Furthermore, PLM is not just a strategy, nor a philosophy about how to organize information. In fact, PLM embraces all of these aspects helping enterprises to achieve business goals.

Although the word approach is vague and not very precise, it allows to widely include in PLM the integration of people, technology, business systems, information, and processes, which are sometimes more important than data [3].
4.2. Phases of Product Lifecycle. An important aspect of PLM is the capacity to manage all the product life cycle phases, from the definition of the product concept to its manufacturing, distribution in the market, and final disposal or recycling. Several authors have tried to specify the PLM phases, such as Ming et al. [13] and Grieves [10].

The lifecycle phases are generally viewed as cyclic and sequential but overlapping can be helpful to guarantee the concurrent and simultaneous engineering reducing lead time and improving quality $[26,27]$. Each phase produces information and uses the information deriving from the other phases, generating an information backbone.

4.3. A Unique and Timed Product Data Source. One of the PLM fundamentals is integrating and storing all data about product in unique and timed sources. Recently, PLM has extended the scope of product data management from $\mathrm{CAD}$ data and engineering drawings to a larger perspective including workflow and processes (e.g., to share information between different design activities) [3].

The need of "uniqueness" emerges from the fragmented product information that resides in different organizational departments and functions (e.g., IT, engineering, manufacturing, and sales) and includes the extended enterprise with its suppliers, business partners, and customers. This means that information is not related not only to product design and manufacturing, but also it encompasses all data indirectly connected to the product structure (e.g., catalogues and customers' and suppliers' feedback). Furthermore, product information is often "hidden" and exists only on an ad hoc basis (e.g., Excel sheets); it is often duplicative and inconsistent because the organizations have the same information in many different forms [10].

In this landscape, useful information can be loose, generating additional costs and inefficiency and slowing down the flow of information that can be instead improved with a PLM approach.

The concept of "timed data" refers to the ability to trace the path of product information through its time and to be informed about the data and their reference period.

Therefore, guarantying the integrity of product information is very important for organizations, especially for those ones working in complex product development such as aerospace companies.

4.4. Consistency, Traceability, and Long-Term Archiving. A PLM system, like unique data source, should make information consistent, traceable, and long-term archiving. "Consistency" refers to the capacity to maintain close links between different data in different versions, so it could be easier to understand what information is being impacted by the change of a data and to facilitate the search for information relating to an object in a particular version. "Traceability", thanks to the consistency of the data, allows to rebuild the whole history of a product keeping track of all its changes and revisions. "Long-term archiving" refers to the ability to retrieve a particular piece of information even after a certain period of time. Even if traceability and long-term 
archiving look like two similar concepts, they have different scopes. The traceability is about providing information about the evolution and changes in the product data during the whole lifecycle; instead the long-term archiving is related to the capacity to store and recover useful information also after many years. For example in the aerospace industry the product lifecycle is longer than 30 years during which it is necessary to guarantee the product support and to respect legal and moral requirements for the dismantling phase.

4.5. Integrating People, Processes, and Technologies. The product lifecycle involves several people, processes, and technologies. They are highly related in a wide net of interactions, and PLM tries to provide an integrated view.

Product data are created and managed by actors with different roles both internal (i.e., employees of different units) and external (i.e., contractors, subcontractors, suppliers, partners, supplier's suppliers, customer's suppliers, customer's customers, etc.) to a company. Each phase of the lifecycle is executed by people involved in processes that can be specific to a product or project or to the organization. All the information generated in the processes is used for realizing the product in a coherent way.

Besides there are many types of systems that can be used across the lifecycle (e.g., CAx tools, ERP; virtual reality systems, and electronic parts catalogues) and that are integrated in the PLM systems $[1,2]$ for tracing data changes and activities performed.

4.6. Collaborate within and across the Extended Enterprise. Complex and knowledge intensive product is often carried out in network of firms to reduce the development cost and to access knowledge and technologies crucial to realize single components or subcomponents [28, 29]. Consequently, the product lifecycle is fragmented among several actors and high level of integration and collaboration is needed. In the extended enterprise (EE), each company specialized in the production of specific goods or services operates in different places, in distinct legal and organizational entities, even if they collaborate to obtain a final product [30] and to manage it in service process. In EEs, firms combine their activities for periods that greatly exceed the lead-times associated with the specific transaction. In this persistence the adoption of PLM approach and specific system finds its adequate context since the companies can build channels between themselves through which information and knowledge can be exchanged and go far beyond the traditional exchange of specifications, drawings, and contracts.

\section{Conclusion}

In industries that produce complex products or operate in complex scenario, the tendency is to use a PLM strategy to integrate all elements (people, processes, business systems, and information) that participate in product development process and support its lifecycle along the value chain. Given the increasing importance of PLM inside the companies to support and guarantee the management of product data during the whole lifecycle, and based on the experiences of a PLM community of practice (Co.PLM), the need of a more wide and integrated definition has emerged.

In the paper, definitions coming from industrial and academic sources have been reviewed using three sets of features (i.e., managerial, technological, and collaborative ones) relevant to the community of practice. From the analysis of the existing definitions, some gaps have emerged. There are mainly a lack, in the analyzed definition, of the concepts of "a unique and timed product data source" and "consistency, traceability and long-term archiving" relevant to the scope of the analysis. Therefore, a definition has been proposed, and the related concepts have been explained. Even if there are several studies available on PLM, the proposed definition extends the state of art introducing a further insight for an immediate and overall view in the PLM both for new practitioners and also old ones. This result has been reached with a high collaboration among the community of practice members and the use of focus groups, webbased tools, and meetings to support the analysis and the definition development. The used methodology is in fact completely original with respect to the previous studies. It combines points of view by different researchers and is highly interactive and based on a strict set of features and dimensions to analysis. The used methodology can be also applied by other communities of practice for their specific needs of research.

Furthermore, the proposal of the three sets of features to analyze PLM is a further innovative contribution of the paper that can be also used by other researchers to design their own PLM investigation.

Finally, further elements could be considered and introduced in the PLM definitions and concepts such as sustainability, user experience, and intelligence but they will be object of future elaborations.

\section{References}

[1] S. G. Lee, Y.-S. Ma, G. L. Thimm, and J. Verstraeten, "Product lifecycle management in aviation maintenance, repair and overhaul," Computers in Industry, vol. 59, no. 2-3, pp. 296-303, 2008.

[2] A. Saaksvuori and A. Immonen, Product Lifecycle Management, Springer, Berlin, Germany, 2nd edition, 2008.

[3] CIMdata, "Product lifecycle management-empowering the future of business," Tech. Rep., 2002, http://www.cimdata .com/publications/pdf/PLM_Definition_0210.pdf.

[4] M. Garetti and S. Terzi, "Product lifecycle management definizione, caratteristiche e questioni aperte," Tech. Rep., Politecnico di Milano, Milano, Italy, 2003, http://coenv.it/bo/ allegati/Files/23_definizione_plm.pdf.

[5] A. P. Hameri and J. Nihtila, "Product data managementexploratory study on state-of-the-art in one-of-a-kind industry," Elsevier Computers in Industry, vol. 35, no. 3, pp. 195-206, 1998.

[6] J. Stark, "Making Progress With PLM," 2005, http://www.johnstark.com/.

[7] PLM Technology Guide, 2008, http://plmtechnologyguide.com/ site/. 
[8] PLM Product Lifecycle Management, 2009, http://productlifecycle-management.com/.

[9] ATOS, 2003, http://atos.net/en-us/home.html.

[10] M. Grieves, Product Lifecycle Management: Driving the Next Generation of Lean Thinking, McGraw-Hill, New York, NY, USA, 2006.

[11] A. Bryman and E. Bell, Business Research Methods, Oxford University Press, Oxford, UK, 2nd edition, 2007.

[12] B. N. Merton, M. Fiske, and P. L. Kendall, The Focused Interview: A Manual of Problems and Procedures, The Free Press, New York, NY, USA, 2nd edition, 1956.

[13] X. G. Ming, J. Q. Yan, X. H. Wang et al., "Collaborative process planning and manufacturing in product lifecycle management," Elsevier Computer in Industry, vol. 59, no. 2-3, pp. 154-166, 2007.

[14] A. Codrino, "Product lifecycle management: approccio integrato per migliorare lo sviluppo dei prodotti," Analisi e Calcolo, no. 29, pp. 6-9, 2008.

[15] Active Sensing Inc., 2008, http://www.activesensing.com/.

[16] Aras Corporation, 2011, http://www.product-lifecycle-management.info/.

[17] Ford Motor Company, "Definition of PLM," in University of Michigan's AUTO, Conference for IT, Engineering, and Manufacturing Automotive Executives, 2004.

[18] R. Sudarsan, S. Foufou, and S. J. Kemmerer, "Analysis of Standards for Lifecycle Management of Systems for US Armya preliminary investigation," Tech. Rep. NISTIR 7339, National Institute of Standard and Technology Administration, Department of Commerce, Gaithersburg, Md, USA, 2006.

[19] B. Stackpole, "There's a new app in town," CIO Magazine, pp. 93-98, 2003.

[20] M. Abramovici, "Future trends in product lifecycle management (PLM)," in The Future of Product Development, F. Krause, Ed., pp. 665-674, Springer, Berlin, Germany, 2007.

[21] A. Osterwalder, Y. Pigneur, and C. L. Tucci, "Clarifying business models: origins, present, and future of the concept," in Communications of the of Association for Information System, pp. 751$775,2005$.

[22] R. M. Rangan, S. M. Rohde, R. Peak, B. Chadha, and P. Bliznakov, "Streamlining product lifecycle processes: a survey of product lifecycle management implementations, directions, and challenges," Journal of Computing and Information Science in Engineering, vol. 5, no. 3, pp. 227-237, 2005.

[23] S. Rachuri, E. Subrahmanian, A. Bouras, S. J. Fenves, S. Foufou, and R. D. Sriram, "Information sharing and exchange in the context of product lifecycle management: role of standards," CAD Computer Aided Design, vol. 40, no. 7, pp. 789-800, 2008.

[24] G. Schuh, H. Rozenfeld, D. Assmus, and E. Zancul, "Process oriented framework to support PLM implementation," Computers in Industry, vol. 59, no. 2-3, pp. 210-218, 2008.

[25] J. Stark, Product Lifecycle Management: 21st Century Paradigm For Product Realisation, Spinger, London, UK, 2011.

[26] J. Ribbens, Simultaneous Engineering for New Product Development, John Wiley \& Sons, New York, NY, USA, 2000.

[27] F. E. Oliveto, "Concurrent engineering: evolution and application," in Proceedings of the IEEE National Aerospace and Electronics Conference (NAECON '00), pp. 737-744, October 2000.

[28] J. Tidd and J. Bessant, Managing Innovation: Integrating Technological, Market and Organizational Change, John Wiley \& Sons, Chichester, UK, 2nd edition, 2009.
[29] P. Trott, Innovation Management and New Product Development, Prentice Hall, London, UK, 3rd edition, 2008.

[30] J. S. Busby and I. S. Fan, "The extended manufacturing enterprise: its nature and its needs," International Journal of Technology Management, vol. 8, no. 3-4, pp. 294-308, 1993. 

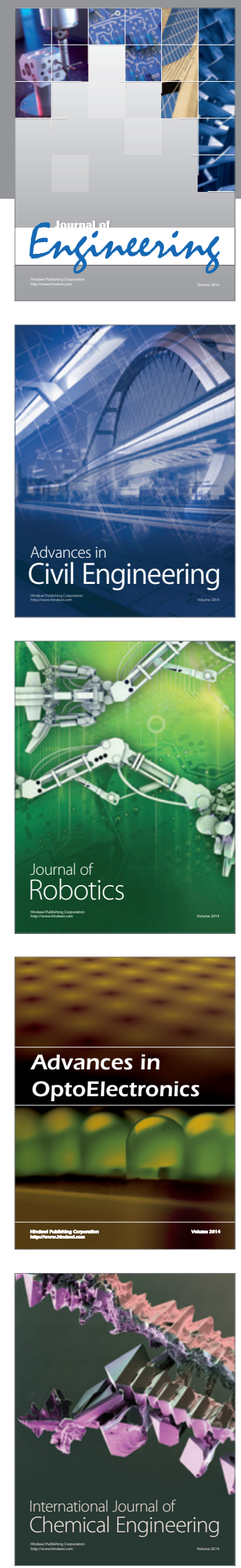

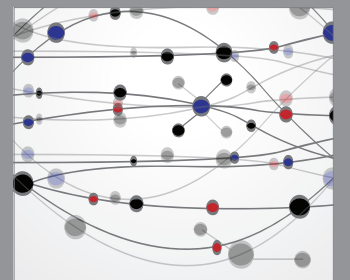

The Scientific World Journal
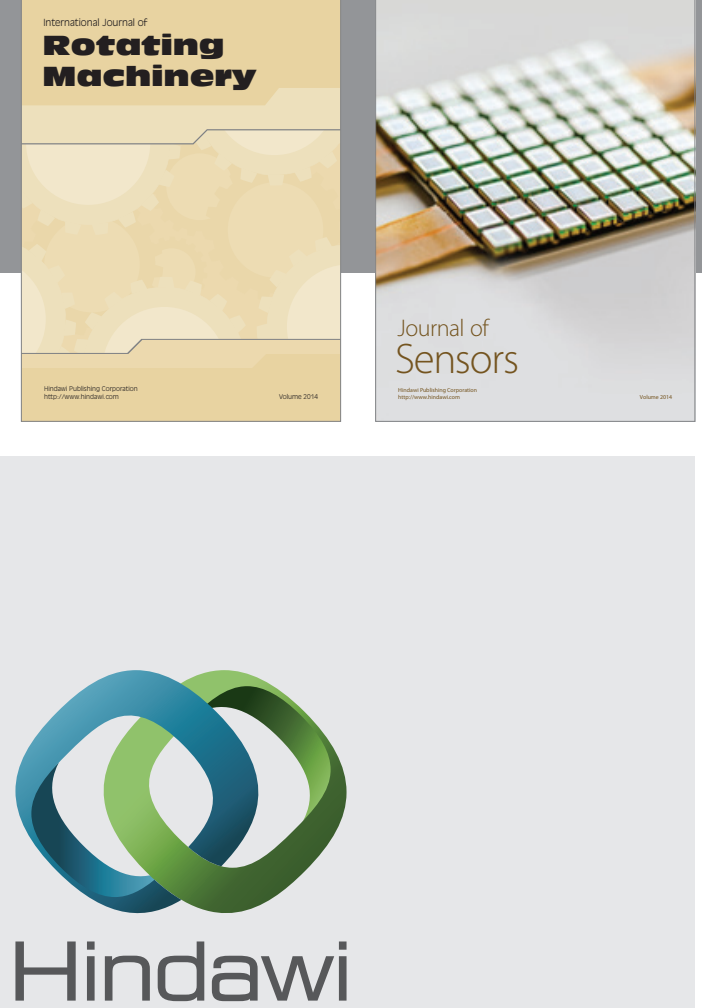

Submit your manuscripts at http://www.hindawi.com
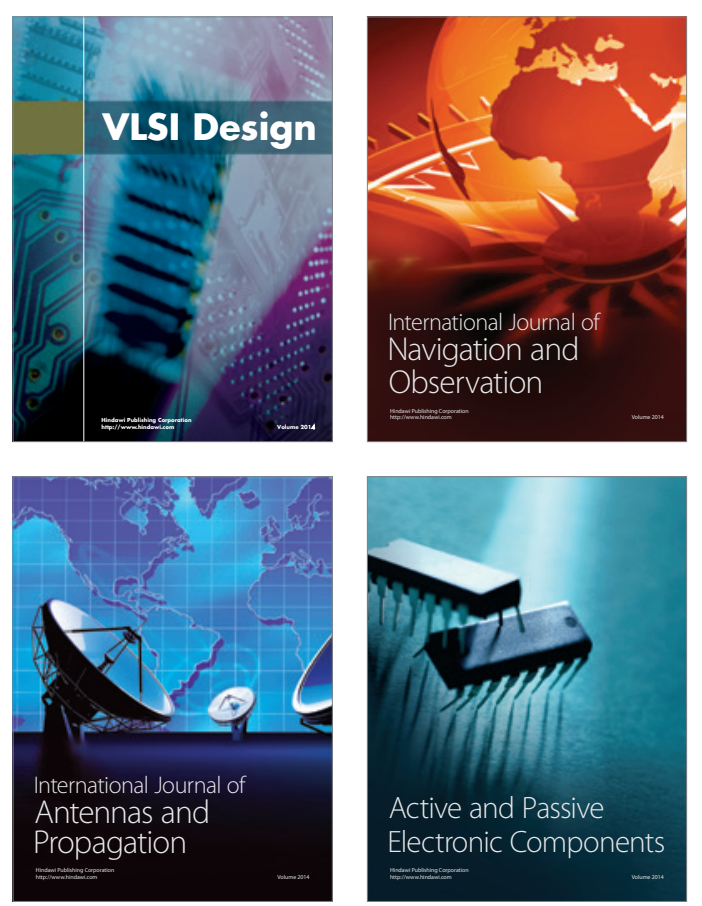
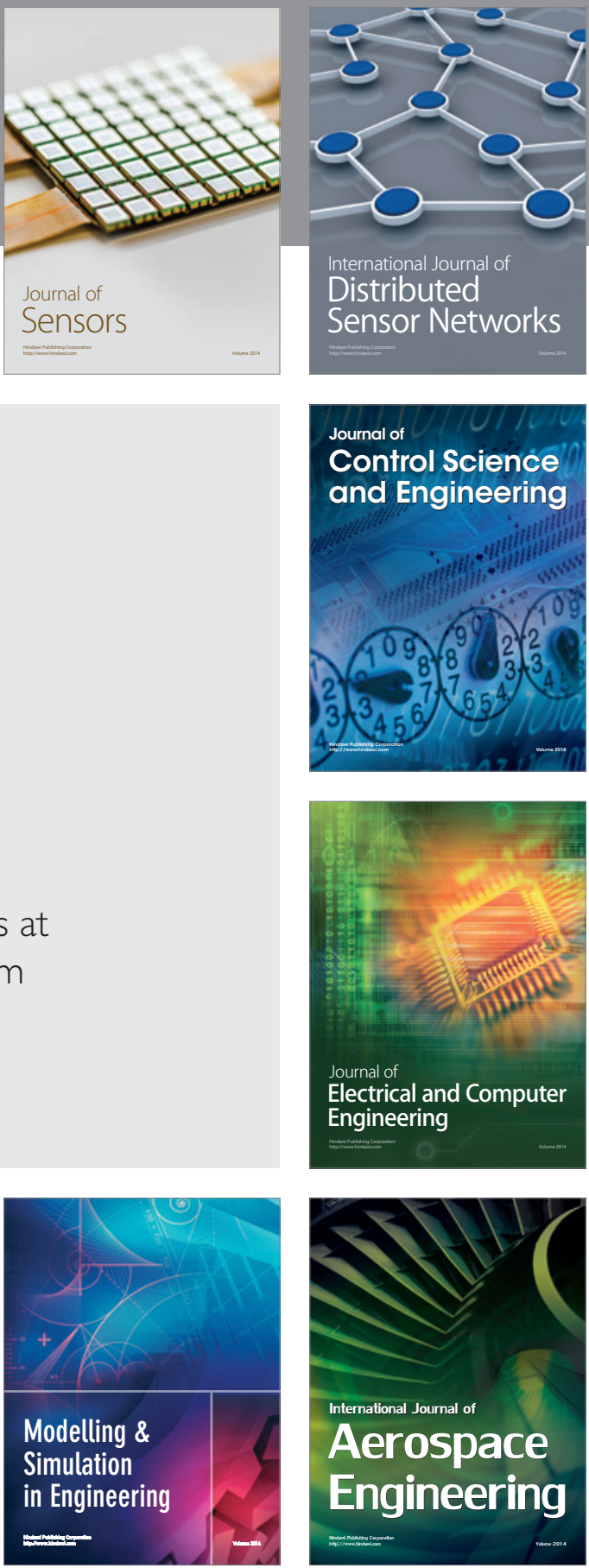

Journal of

Control Science

and Engineering
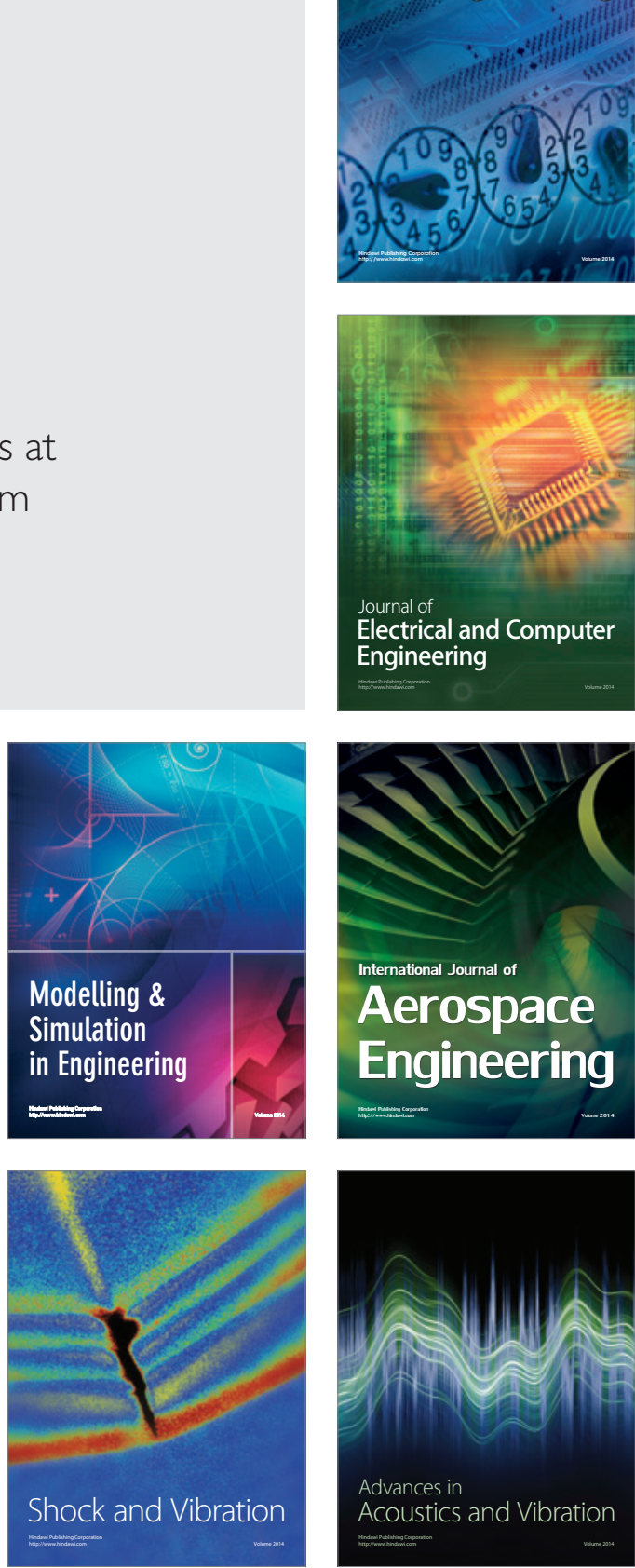